\title{
A Novel Preparation of Polyimide/Clay Hybrid Films with Low Coefficient of Thermal Expansion
}

\author{
AIJUAN GU, ${ }^{1}$ FENG-CHIH CHANG ${ }^{2}$ \\ ${ }^{1}$ Institute of Polymer Composites, Department of Polymer Science \& Engineering, Zhejiang University, Hangzhou, \\ Zhejiang 310027, People's Republic of China \\ ${ }^{2}$ Department of Applied Chemistry, National Chiao Tung University Hsin-Chu, Taiwan 30050
}

Received 18 January 2000; accepted 27 February 2000

\begin{abstract}
A novel polyimide (PI)/clay hybrid nanocomposite, designated as PI (PAAS)/CM, has been developed from the poly(amic acid) salt of triethylamine and organomontmorillonite (CM) using a mixture solution of tetrahydrofuran (THF) and methanol (MeOH). For comparison, two other PI/clay hybrids derived from poly(amic acid) and $\mathrm{CM}$ in THF/MeOH solution and $N, N^{\prime}$-dimethylacetamide (DMAc) solution, denoted as PI/CM (T/M) and PI/CM (DMAc), respectively, were also prepared. Dispersion of CM in polymer matrix, tensile properties, and thermal expansion properties of the three hybrids were investigated. Results show that PI (PAAS)/CM has the best dispersion of CM in polymer matrix, highest elongation, and lowest coefficient of thermal expansion values in all hybrids presented in this report. In addition, PI/CM (T/M) has better dispersion of CM and lower coefficient of thermal expansion value than PI/CM (DMAc). @ 2000 John Wiley \& Sons, Inc. J Appl Polym Sci 79: 289-294, 2001
\end{abstract}

Key words: polyimide hybrids; coefficient of thermal expansion; montmorillonite; poly(amic acid) of salt; tetrahydrofuran; methanol

\section{INTRODUCTION}

With the increasing and urgent market demand to produce higher-performance electronic devices with smaller size, lighter weight, and better quality, developing polyimide (PI) films with low coefficient of thermal expansion (CTE) has increasingly become one of the most important issues. ${ }^{1-8}$ This is because this kind of PI overcomes the thermal stress concentration and associated reliability problem produced by the mismatch in CTE between polymers, metals, and ceramics that make up electronic devices, and hence, enables

Correspondence to: A. Gu (ipczju@dial.zju.edu.cn).

Contract grant sponsor: Cao Guang-Biao Foundation of Science and High Technology, Zhejiang University.

Journal of Applied Polymer Science, Vol. 79, 289-294 (2001)

(C) 2000 John Wiley \& Sons, Inc.
PIs to meet some ultimate requirements in demanding applications such as high-speed circuits and complex multilayer devices. To date, one of the best ways to lower the CTE of PI is to introduce low CTE inorganic materials such as clay into the PI matrix, yielding PI/clay hybrid nanocomposites. The conventional preparation method of PI/clay hybrids is similar to the traditional method of making pure PI; that is, first, an aromatic dianhydride is added to a solution of an aromatic diamine in a polar aprotic solvent such as $N, N^{\prime}$-dimethylformamide, $N, N^{\prime}$-dimethylacetamide (DMAc), or $N$-methylpyrrolidone at room temperature to form poly(amic acid) (PAA); second, vigorously mixing the solution of poly(amic acid) and the solution of organoclay; third, converting the mixture to PI/clay films by thermal curing. Although PI/clay hybrids thus synthe- 
sized usually have lower CTE, higher thermal stability, lower moisture absorption, higher hardness, and better barrier resistance as well as superior scratch resistance compared with neat $\mathrm{PIs},{ }^{9-11}$ this synthesis method impedes the full expression of potential properties of PI/clay hybrids because of several disadvantages. It is well known that the polar aprotic solvents used for synthesis of hybrids have a strong solvent-solute interaction and are not easily removed from the PAA film at temperatures used during thermal curing for PI. ${ }^{12-14}$ The residual solvent causes the PAA/clay films to be plasticized during thermal imidization and thus leads to PI/clay hybrid films with relatively higher values in CTE but with lower CTE than pure PI film. To eliminate such negative effects of the aprotic solvents on CTE, PAA solutions not containing them should be prepared. In addition, the PAA solution is not stable during storage. ${ }^{3}$ It is necessary to prepare other PI precursors such as PAA esters, and PAA salts, etc. without storage problem in solution,

In 1995, Echigo et al. ${ }^{15,16}$ first developed a novel solution polymerization of pyromellitic dianhydride (PMDA) and 4,4'-oxydianiline (ODA) in a mixed solvent of tetrahydrofuran (THF)/ methanol (MeOH). PI film thus prepared has a lower value of CTE compared with that from a PAA solution using $N$-methylpyrrolidone. In addition, they used a similar method to prepare a poly[bis(trialkylammonium) 4,4'-oxydiphenylenepyromellitamate] film containing no residual solvents, the resulting PI film having a reduced CTE compared to that using PAA as precursor. ${ }^{17}$ Also, another research group developed PI-silica hybrids by sol-gel technology in a mixed THF/ $\mathrm{MeOH}$ solvent. ${ }^{18,19}$ In comparison, polyimide hybrids prepared from THF/MeOH have smaller domain size and CTE than those prepared from DMAc.

To date, the preparation of PI/clay hybrids without using aprotic solvents has not been reported. In this article, a novel PI/clay hybrid film prepared from PAA salt of triethylamine and organoclay in a mixed solvent of THF/MeOH is described. It is expected that the hybrid will have a much lower CTE than those obtained from PAA in aprotic solvent.

\section{EXPERIMENTAL}

\section{Materials}

Montmorillonite "Kunipia F," a sodium montmorillonite (MMT), with cation exchange capacity of ca. $115 \mathrm{meq} / 100 \mathrm{~g}$, was obtained from Kunimine Ind. Co. of Japan. Cetyl pyridium chloride was supplied by Sigma Chemical (St. Louis, MO) with purity greater than $99 \%$, and was used as received. The ultra pure (99.5\%) PMDA and ODA were purchased from Chriskev Inc. (USA). The analysis grade triethylamine $\left(\mathrm{Et}_{3} \mathrm{~A}\right)$ obtained from Shanghai Chemicals, China, was used as received. DMAC, THF, and $\mathrm{MeOH}$ were purchased from Shanghai Chemicals, China, and were dehydrated by distillation and stored using molecular sieves.

\section{Preparation of Organophilic Clay}

One gram of MMT was added into $50 \mathrm{~mL}$ of water until the MMT was well dispersed in the water, equal molar cetyl pyridium chloride was added to the solution, and the mixture was stirred vigorously for $24 \mathrm{~h}$. The resulting organoclay was collected by filtering, then washing with deionized water several times until no $\mathrm{Cl}^{-}$was detected by $\mathrm{AgNO}_{3}$, and designated as CM.

\section{Preparation of PAA Salt of Triethylamine/CM Solution}

PAA salt of $\mathrm{Et}_{3} \mathrm{~A}$ was prepared following the process cited in previous articles. ${ }^{12,13}$

A typical example of preparing a $\mathrm{THF} / \mathrm{MeOH}$ solution of poly[bis (trialkylammonium) 4,4'-oxydiphenylenepyromellitamate] containing $3 \mathrm{wt} \%$ $\mathrm{CM}$ is as follows.

A three-necked flask fitted with a mechanical stirrer and thermometer were charged with 20.02 $\mathrm{g}(0.1 \mathrm{~mol})$ of ODA, $420 \mathrm{~g}$ THF/MeOH $(\mathrm{THF} /$ $\mathrm{MeOH}=4: 1$ by weight). After ODA had completely dissolved, $22.90 \mathrm{~g}(0.105 \mathrm{~mol})$ of PMDA powder was added gradually into the stirring solution of the diamine over $40 \mathrm{~min}$ at room temperature. The stirring continued at room temperature for $3 \mathrm{~h}$. Then a mixture of $\mathrm{Et}_{3} \mathrm{~A} 25.55 \mathrm{~g}$ (0.252 mol) and $\mathrm{MeOH} 168 \mathrm{~g}$ was added dropwise with stirring at room temperature. This process took $3 \mathrm{~h}$ to complete and a viscous, pale yellow solution was obtained.

A mixture of $0.1381 \mathrm{~g}$ of $\mathrm{CM}$ and $5.77 \mathrm{~mL}$ of $\mathrm{THF} / \mathrm{MeOH}$ (4:1 by weight) was stirred vigorously at $90^{\circ} \mathrm{C}$ for $24 \mathrm{~h}$ to yield $\mathrm{THF} / \mathrm{MeOH}$ dispersion of CM.

The THF/MeOH solution of $\mathrm{CM}$ obtained was placed into the $\mathrm{THF} / \mathrm{MeOH}$ solution of poly[bis(trialkylammonium) 4,4'-oxydiphenylenepyromellitamate] and stirred vigorously at $30^{\circ} \mathrm{C}$ for 


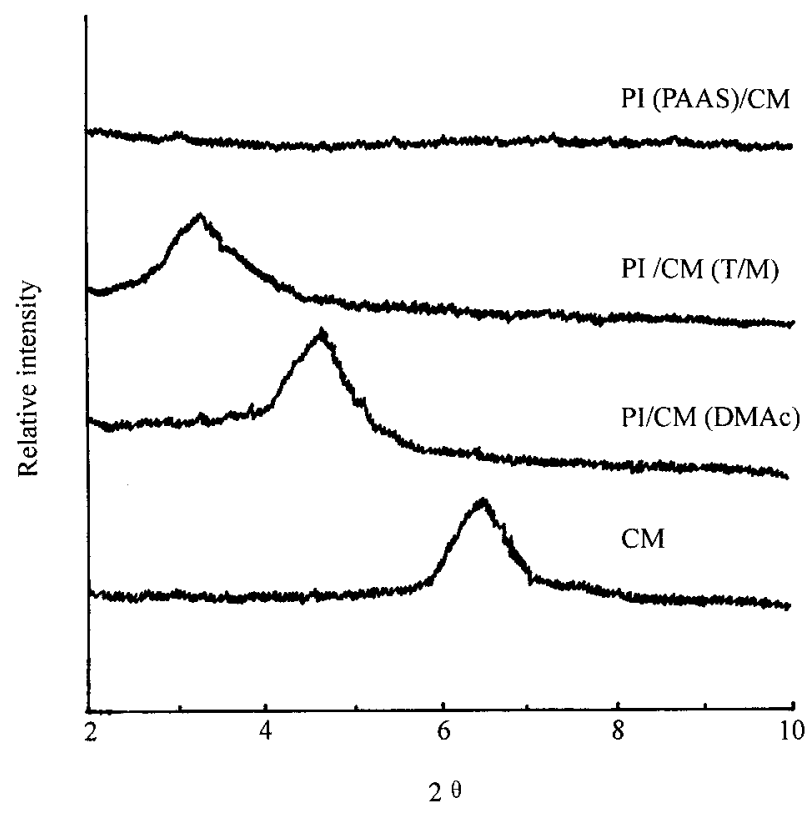

Figure 1 X-ray diffraction patterns of polyimide hybrids and organoclay.

$6 \mathrm{~h}$, yielding a THF/MeOH solution of PAA salt of triethylamine.

For comparison, two homogeneous yellow $\mathrm{PAA} / \mathrm{CM}$ solutions were prepared in $\mathrm{THF} / \mathrm{MeOH}$ and DMAc solutions, respectively.

\section{Preparation of PAA Salt/CM and PI/Clay Hybrid Films}

The prepared THF/MeOH solution of poly[bis(trialkylammonium) 4,4'-oxydiphenylenepyromellitamate]/CM was coated by a doctor blade on a glass plate using an automatic film applicator moved at a speed of $30 \mathrm{~mm} / \mathrm{s}$ and to a thickness of $250 \mu \mathrm{m}$. The coated film was dried at $25^{\circ} \mathrm{C}$ for 30 min, $40^{\circ} \mathrm{C}$ for $30 \mathrm{~min}$, and $80^{\circ} \mathrm{C}$ for $2 \mathrm{~h}$, subsequently, to yield a transparent film. The film was removed from the glass plate and was denoted as PAAS/CM film. The film was then cured at 150, 200 , and $300^{\circ} \mathrm{C}$ for $1 \mathrm{~h}, 1 \mathrm{~h}$, and $2 \mathrm{~h}$, successively, under a nitrogen atmosphere to produce a transparent PI (PAA)/CM hybrid film with a thickness of $26 \pm 2 \mu \mathrm{m}$.

$\mathrm{PAA} / \mathrm{CM}$ films were prepared by the same method from THF/MeOH solution and DMAc solution, designated as PAA/CM (T/M) and PAA/CM (DMAc). The films were also thermally cured to obtain transparent polyimide/clay hybrid films, coded as PI/CM (T/M) and PI/CM (DMAc), respectively. In addition, pure polyimide film prepared from PAA using DMAc was synthesized, and is denoted as PI (DMAc).

\section{Characterization}

A Fourier transform infrared spectra measurement was recorded on a Nicolet Avatar 320 Fourier Transform Infrared Spectrophotometer. For all infrared spectra, 32 co-added scans were collected with a spectral resolution of $2 \mathrm{~cm}^{-1}$. Wideangle diffraction experiments were conducted on a Rigaku X-ray Diffractometer using $\mathrm{Cu}$-Ka radiation (18 kw rotating anode, $\lambda=1.5405 \AA$ ). It was operated at $50 \mathrm{kv}, 250 \mathrm{~mA}$ with a scan speed of $2.00 \mathrm{deg} / \mathrm{min}$. CTE in the film plane was measured in the extension mode using a Thermomechanical Analyzer (TA Instruments, model no. 2940 ) with a force of $0.05 N$. Tensile mechanical properties of the cured films were measured using a Micro-Computer Universal Materials Tester, Model-HT-8116 (Hung Ta Instrument Co., Ltd., Taiwan) at room temperature. Samples sized 150-mm long, 25.4-mm wide, and $26 \pm 2-\mu \mathrm{m}$ thick were cut from free films. The gauge length was $\approx 110 \mathrm{~mm}$. The strain rate was $10 \mathrm{~mm} / \mathrm{min}$. The thermal gravimetric analysis was conducted on a Thermogravimetric Analyzer (TA Instruments, model no. 2950) under a nitrogen atmosphere flow with a heating rate of $10^{\circ} \mathrm{C} / \mathrm{min}$.

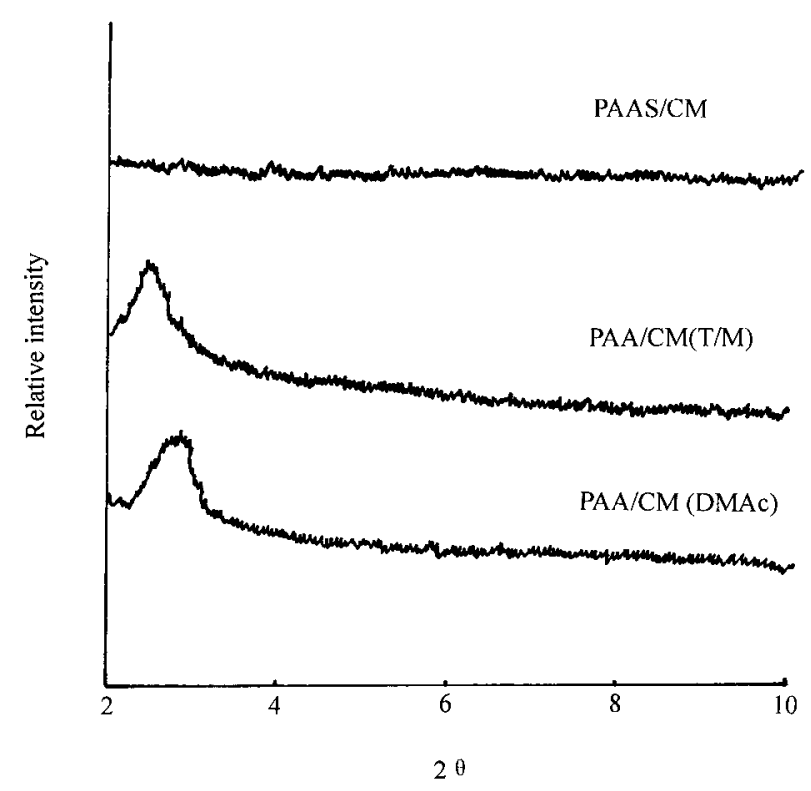

Figure 2 X-ray diffraction patterns of precursor films. 
Table I Tensile Properties of Polyimide Hybrids

\begin{tabular}{lcccc}
\hline & PI (PAAS)/CM & PI/CM (T/M) & PI/CM (DMAc) & PI (DMAc) \\
\hline Tensile strength (MPa) & 110 & 109 & 107 & 83 \\
Tensile modulus (GPa) & 2.38 & 2.38 & 2.37 & 1.65 \\
Tensile elongation $(\%)$ & 11 & 9.9 & 9.6 & 8.7 \\
\hline
\end{tabular}

\section{RESULTS AND DISCUSSION}

\section{Dispersion of CM in Polymer Matrix}

The efficiency of clay to modify the properties of the polymer is primarily determined by the degree of its dispersion in the polymer matrix. Hybrids with poor dispersion of clay in polymer matrix usually have higher modulus, but lower toughness. It has been suggested that, when the stacked silica sheets of clay are completely dispersed (exfoliation) in the polymer matrix, the hybrids will have the best integrated properties. $^{20,21}$ Figure 1 shows the X-ray diffraction curves of PI/clay hybrids in the region from $2 \theta$ $=2^{\circ}$ to $2 \theta=10^{\circ}$. The curve of the PI(PAAS $) / C M$ film shows no peak in the region from $2 \theta=2^{\circ}$ to $2 \theta=10^{\circ}$. This fact reveals that $\mathrm{CM}$ in the polymer matrix has no specific interlayer spacing and $\mathrm{CM}$ disperses homogeneously into the PI matrix. Each of the other two curves has one peak which is assigned to the 001 lattic spacing of organoclay, corresponding to an interlayer spacing of organoclay. The $2 \theta$ values are in the following order: $\mathrm{PI}(\mathrm{PAAS}) / \mathrm{CM}<\mathrm{PI} / \mathrm{CM}(\mathrm{T} / \mathrm{M})<\mathrm{PI} / \mathrm{CM}(\mathrm{DMAc})$. This is because PAA associates with solvents and cannot be removed easily from PAA film at the temperatures used during thermal curing from PAA to PI. In addition, when intercalated solvent is eliminated from sheets of clay, it can draw some intercalated polymer out of the clay sheets at the same time. This can be confirmed from the $2 \theta$ values in the $\mathrm{X}$-ray diffraction curves of $\mathrm{PAA} / \mathrm{CM}$ (T/M) and PAA/CM (DMAc) films (Fig. 2), both of them being larger than that of cured polymer/clay hybrid films (Fig. 1).

\section{Tensile Properties of PI/CM Hybrid Films}

The residual stress that is built into a PI film can cause the film to crack and, in severe cases, to initiate the destruction of the electronic devices. Better elongation properties of PI films make it possible to avoid the undesirable failure under mechanical/thermal stress. Table I lists the tensile properties of hybrid films. Tensile strength, modulus, and elongation of all hybrids are better than that of pure PI. A noteworthy phenomenon is that PI (PAAS)/CM has the higher elongation than other films, which may be attributed to the good dispersion of CM in polymer matrix.

\section{CTE}

Table II gives the CTE of hybrids; it can be seen that all hybrid films have smaller CTE values than pure PI film because of the smaller CTE of the inorganic material, whereas $\mathrm{PI}(\mathrm{PAAS}) / \mathrm{CM}$ has the lowest CTE in the four polyimide films presented in this Table. In addition, the solvent used for synthesizing hybrids has a great effect on CTE of hybrids. Even when both are prepared from PAA, the hybrid film using THF/MeOH as solution has a much smaller CTE than that using DMAc as solution.

It is well known that CTE relates to the degree of in-plane orientation of PI film, which greatly depends on the amount and nature of the residual

Table II Imidization Degree of Incompletely Imidized Hybrids

\begin{tabular}{llcc}
\hline & Drying and Curing Cycle & Imidization Degree (\%) & Weight Loss of Water (\%) \\
\hline PI (PAAS)/CM (T/M) & $80^{\circ} \mathrm{C} / 2 \mathrm{~h}$ & 1.7 & 0.15 \\
& $80^{\circ} \mathrm{C} / 2 \mathrm{~h}+150^{\circ} \mathrm{C} / 1 \mathrm{~h}$ & 84 & 7.23 \\
$\mathrm{PI} / \mathrm{CM}(\mathrm{T} / \mathrm{M})$ & $80^{\circ} \mathrm{C} / 2 \mathrm{~h}$ & 0.9 & 0.08 \\
& $80^{\circ} \mathrm{C} / 2 \mathrm{~h}+150^{\circ} \mathrm{C} / 1 \mathrm{~h}$ & 67 & 5.77 \\
$\mathrm{PI} / \mathrm{CM}(\mathrm{DMAc})$ & $80^{\circ} \mathrm{C} / 2 \mathrm{~h}$ & 0 & 0 \\
& $80^{\circ} \mathrm{C} / 2 \mathrm{~h}+150^{\circ} \mathrm{C} / 1 \mathrm{~h}$ & 34 & 2.77 \\
\hline
\end{tabular}


solvents in the precursor films. Solvate formations between PAA and DMAc, or THF/MeOH, and that between PAA salt and THF/MeOH was reported in previous literature ${ }^{12,15}$ but these films were pure PAA or PAAS and did not contain clay, so it was necessary to investigate the solvate formation in the present PAA/CM and PAAS/CM hybrid films due to the presence of CM.

The degree of imidization is determined by comparing the intensity of the imide absorption near $1380 \mathrm{~cm}^{-1}$ (C-N stretch), which does not appear to be affected by any other absorption, ${ }^{12,22,23}$ in a treated sample compared with that of a completely imidized sample. ${ }^{23}$ The results are presented in Table II.

Figure 3 gives the thermogravimetric analysis curves of PAAS/CM, PAA/CM (T/M), and PAA/CM (DMAc) films at $150^{\circ} \mathrm{C}$ under a nitrogen atmosphere. Samples were heated from room temperature to $150^{\circ} \mathrm{C}$ at a heating rate of $10^{\circ} \mathrm{C} / \mathrm{min}$. In the case of PAAS/CM film, its weight loss is $7.1 \%$ after $1 \mathrm{~h}$, which equals to the theoretical weight loss of water of cyclization, calculated based on the degree of imidization (Table I) under the same curing conditions. The result indicates that no residual solvent exists in the film after drying at $80^{\circ} \mathrm{C}$ for $2 \mathrm{~h}$. This can also be confirmed by the absence of the absorption band at $1051 \mathrm{~cm}^{-1}$ attributed to the antisymmetrical stretching of THF in PAAS/CM film. On the contrary, the isothermal weight losses at $150^{\circ} \mathrm{C}$ for $1 \mathrm{~h}$ of PA/CM (T/M) and PAA/CM (DMAc) are much larger than the

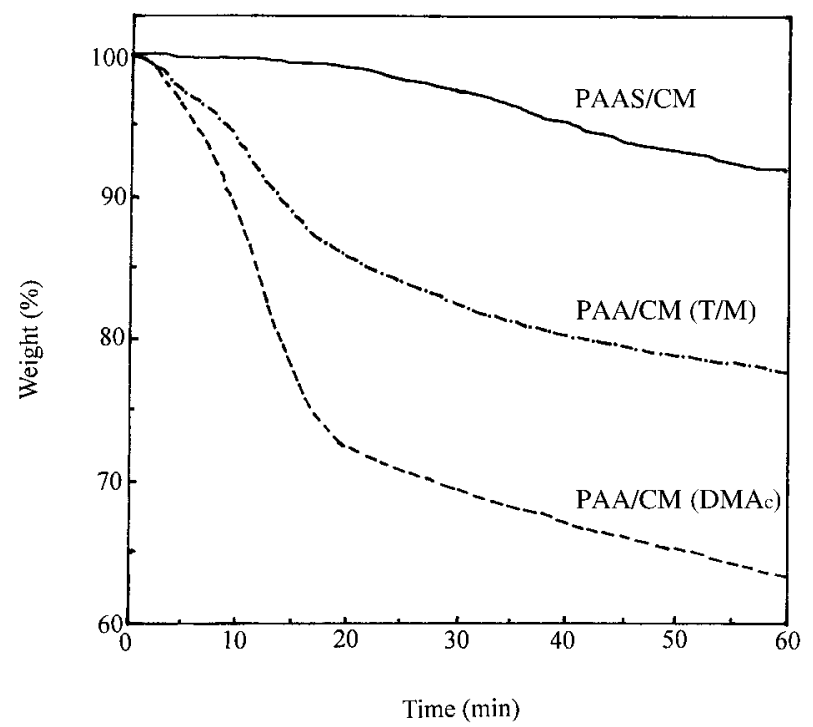

Figure 3 Isothermal thermogravimetric analysis curves of polymer hybrids at $150^{\circ} \mathrm{C}$.
Table III CTE of PI/Clay and PI Films

\begin{tabular}{lc}
\hline & $\mathrm{CTE}\left(\mathrm{ppm} /{ }^{\circ} \mathrm{C}\right)$ \\
\hline PI (PAAS)/CM & $8(35.29 \%)$ \\
PI/CM (T/M) & $27(52.94 \%)$ \\
PI/CM (DMAc) & $40(78.43 \%)$ \\
PI (DMAc) & $51(100 \%)$ \\
\hline
\end{tabular}

theoretical weight loss of water of cyclization, especially in the case of the PAA/CM (DMAc) film. So there are residual solvents in the two films despite drying at $80^{\circ} \mathrm{C}$ for $2 \mathrm{~h}$. The results agree with the conclusion reported in the literature, ${ }^{12,15}$ in which films were pristine PAA or PAAS films and did not contain clay. Because there is no residual solvent in PI (PAAS)/CM film during the thermal curing, the film has the lowest CTE value compared to other films that have residual solvents during thermal imidization (Table III).

However, although the other two polyimide hybrids films from PAA have residual solvents, the nature of the solvents are different and have an important effect on mobility and plasticization of polymer chains. THF alone cannot dissolve PAA, but DMAc can, so the degree of plasticization in $\mathrm{PAA} / \mathrm{CM}$ (DMAc) film is higher than that in PAA/CM (T/M) film, resulting in the CTE value of $\mathrm{PI} / \mathrm{CM}$ (DMAc) being bigger than that of PI/CM (T/M) film.

\section{CONCLUSIONS}

PI (PAAS)/CM, prepared from PAA salt and organo-montmorillonite in a mixture solution of $\mathrm{THF} / \mathrm{MeOH}$ has been developed. Montmorillonite was homogeneously dispersed in polymer matrix. After drying at $80^{\circ} \mathrm{C}$ for $2 \mathrm{~h}$, no residual solvent was present in the precursor film, PAAS/CM, of hybrid but still was present in PAA/CM films no matter whether THF/MeOH or DMAc was used as reaction solution. By thermal imidization, PI (PAAS)/CM hybrid film has lower CTE and better tensile elongation than those prepared from PAA in $\mathrm{THF} / \mathrm{MeOH}$ solution or DMAc solution.

The financial support provided by the Cao Guang-Biao Foundation of Science and High Technology, Zhejiang University, is greatly appreciated.

\section{REFERENCES}

1. Auman, B. C.; Myers, T. L.; Higley, D. P. J Polym Sci A Polym Chem 1997, 35, 2441-2451. 
2. Miwa, T.; Okabo, Y.; Ishida, M. Polymer 1997, 38, 4945-4949.

3. Wilson, D.; Strenzenberger, H. D.; Hergenrother, P. M. Polyimides; Blackie: New York, 1990.

4. Numata, S.; Ohara, S.; Imaizumi, J.; Kinjo, N. Polym J 1985, 17, 981-984.

5. Sysel, P.; Pulec, R.; Maryska, M. Polym J 1997, 29, 607-610.

6. Mascia, L.; Kioul, A. J Mater Sci Lett 1994, 13, 641-643.

7. Mascia, L.; Kioul, A. Polymer 1995, 36, 3649-3656.

8. Morikawa, A.; Iyoku, Y.; Kakimoto, M.; Imai, Y. Polym J 1992, 24,107-113.

9. Yano, K.; Usuki, A.; Okada, A. J Polym Sci A Polym Chem 1997, 35, 2289-2294.

10. Lan, T., Kaviratna, P. D.; Pinnavaia, T. J. Chem Mater 1994, 6, 573-575.

11. Yano, K.; Usuki, A.; Okada, A.; Kurauchi, T.; Kamigaito, O. J Polym Sci A Polym Chem 1993, 31, 2493-2498.

12. Kreuz, J. A.; Endrey, A. L.; Gay, F. P.; Sroog, C. E. J Polym Sci A-1 1966, 4, 2607-2615.
13. Brekner, M. J.; Feger, C. J Polym Sci Polym Chem Ed 1987, 25, 2005-2011.

14. Feger, C. Polym Eng Sci 1989, 29, 347-351.

15. Echigo, Y.; Iwaya, Y.; Tomioka, I.; Yamada, H. Macromolecules 1995, 28, 4861-4865.

16. Echigo, Y.; Iwaya, Y.; Saito, M.; Tomioka, I.; Furukawa, M.; Okamuto, S. Macromolecules 1995, 28, 3000-3001.

17. Echigo, Y.; Miki, N.; Tomioka, I. J Polym Sci A Polym Chem 1997, 35, 2493-2498.

18. Morikawa, A.; Yamaguchi, H.; Kakimoto, M.; Imai, Y. Chem Mater 1994, 6, 913-917.

19. Iyoku, Y.; Kakimoto, M.; Imai, Y. High Perform Polym 1994, 6, 95-107.

20. Vaia, R. A. Chem Mater 1993, 5, 1694-1696.

21. Moet, A. Mater Res Soc Symp Proc 1994, 351, 9193.

22. Pryde, C. A. J Polym Sci A 1989, 27, 711-719.

23. Bessonov, M. I.; Koton, M. M.; Kudryavtsev, V. V.; Laius, L. A. Polyimdes: Thermally Stable Polymers, 2nd ed.; Plenum: New York, 1987; pp. 1-95. 